\title{
XXXII. The tails of comets
}

\section{E. Vansittart Neale}

To cite this article: E. Vansittart Neale (1882) XXXII. The tails of comets, Philosophical Magazine Series 5, 14:88, 292-294, DOI: $10.1080 / 14786448208627266$

To link to this article: http://dx.doi.org/10.1080/14786448208627266

册 Published online: 08 Jun 2010.

Submit your article to this journal

Џ Article views: 2

Q View related articles $₫$ 


\section{[ 292$]$}

XXXII. The Tails of Comets.

By E. Vansittart Neale.

\section{T'o the Editors of the Philosophical Magazine and Journal.}

\section{GentLemen,}

T VENTURE to offer an explanation of the remarkable 1 phenomena presented by the tails of comets, so simple that, considering the number of eminent astronomers who have turned their attention to this subject, and to whom it has remained a mystery, I am almost afraid to suggest my explanation, lest it should prove a sort of scientific mare's nest. Still, since I caunot see where it fails, while the subject is one of considerable interest, I have determined to run the risk of some eye more penetrating than my own discovering my error, if there is one.

My explanation rests on the internction of three forces, of which two are known to exist, while the existence of the third may, I think, be reasonably assumed. These forces are:(1) the force which urges the comet towards the sun; (2) the expansive force of the heat of the sun; (3) the resistance of an atmosphere surrounding the sun.

That there is such an atmosphere extending many hundred thousand miles from the sun's centre we know, because it can be seen. How much further it may extend in a condition in which it is invisible we do not know; but, considering the distance to which the atmosphere surrounding the earth is known to extend by its action on meteoric bodies, we may, I think, reasonably assume the existence of an invisible solar atmosphere, extending far beyoud the limits of the visible atmosphere; and if this is assumed, we obtain an easy explanation of the phenomena of comets' tails.

The changes in a comet which give rise to its tail begin, according to the account given by Mr. Higgins in his excellent article on Comets in the current number of the 'Nineteenth Century,' by jets of a gaseous nature ejected towards the sun, $i . e$. in the direction determined by the expansive force of the sun's heat, acting on the comet, combined with the moving force of the comet. But soon, he says, these jets bend round, as if they were carried back by a strong wind, and form an envelope round the body of the comet and a cone behind it. Just so. It is what would happen to a man dressed in a loose robe and running rapidly through the air. His dress, though moving with him, would stream behind him, because it experienced more resistance than his body from the air. The jets 
of gas which escape from the body of the comet and expand when they leare it are more resisted by the sun's atmosphere than its more solid head, which therefore gradually orertakes them ; so that they seem to fall back, till they constitute an envelope round it, and then spread in a conical form behind the head, through the joint operation of their own lateral movements, of the increasing expansive force of the sun's heat as the comet approaches the sun, of the increasing resistance of the sun's atmosphere (whence the head must continually gain more and more on the parts of the tail at first thrown off), and of the pressure of fresh envelopes continually forming round the nucleus as it advances. The body of the comet is constantly moving through the gases or vapours which it throws off, and thus produces the appearance of a tail, by leaving each successive part thrown off more and more behind it.

The central line of these successive envelopes would obviously tend to be a straight line from the sun's centre through the head of the comet; though the continual change of direction in this line, as the comet approaches its perihelion, must be liable to produce an apparent curvature in the tail, because the parts first emitted, and therefore most distant from the body, if they retain luminosity enough to be visible, must fall more and more behind the advance of this central line in its sweep round the sun.

The phenomena of divided tails, of bright streaks, \&c., find a ready explanation in the accidental variety of pressures to be expected among jets of gas or vapour emitted under such circumstances, and the effect of perspective, according as we happen to look through the edges or across the more central parts of the envelopes forming the comet's tail--possibly combined with actual variations of pressure in the sun's invisible atmosphere, arising out of the enormous changes which can be observed in its visible atmosphere. But what as to the change in the direction of the tail when a comet has passed its perihelion? Why do comets then carry their tails before instead of behind their heads? Because the direction of the pressures which produce the tail has changed. Given an invisible solar atmosphere, a comet moving towards the sun will be perpetually passing from a rarer into a denser medium, while a comet moving from the sun will be perpetually passing from a denser into a rarer medium. At the same time the jets of gases or vapours which it will continue to emit from the expansive force of the sun's heat will then consist of particles moving from the sun. Thus the two tendencies-the movement of these particles due to the action of gravity, and the tendency of the expansive force to exert itself in the line of 
least resistance-will combine to carry the luminous particles emitted from the comet in advance of the mass.

That the change in the direction of a comet's tail should take place with the rapidity and to the extent observed in the case of the enormous appendages of some of these bodies may still appear surprising. But it must be remembered that, in these cases, we can speak only of what we see. The conical mass of gases or vapours extending behind the nucleus of a comet may attain, in the case of the largest of these bodies, to an expansion much greater than the part visible, which may consist only of the parts that receive the strongest impulses from the centre of force; so that when the tail seems to have swung round through an enormous are in the sky, what has really happened may be only that the line along which the substances forming it become visible may have shifted, in consequence of the direction of the impulses proceeding from the head having altered.

As the time when the most rapid alteration in the direction of the tail of a comet takes place necessarily coincides with that when the expansive action of the sun on the substances emitted from the comet is at its maximum, there must be the less difficulty in admitting the last hypothesis as an explanation of this phenomenon. It is the only one, so far as I see, that offers any difficulty in the way of the theory now proposed respecting the tails of comets, which may be summed up in the proposition that, as the incandescence of meteoric bodies proves to us the existence of a widely diffused atmosphere surrounding the earth, so the development of the tails of Comets proves to us the existence of a much more widely diffused atmosphere surrounding the sun-both sets of phenomena being due to the same cause, namely the resistance of these atmospheres to bodies rapidly passing through them.

I am yours \&c.,

E. Vansittart Neale.

15 Portsmouth Street, Manchester,

August 21, 1882.

XXXIII. Simple Method for Calibrating Thermometers. By Silas W. Holman*.

THE calibration of a thermometer by most of the methods 1 in ordinary use is a tedious and somewhat difficult operation, and hence often neglected even in important work. For the purpose of supplying a method simple both in observation and computation, and at the same time accurate, the following

* From Silliman's American Journal, No, 136, p. 278. 